\title{
Association with terminal exons in pre- mRNAs: a new role for the U1 snRNP?
}

\author{
Karen Montzka Wassarman' ${ }^{1}$ and Joan A. Steitz ${ }^{2}$ \\ Department of Molecular Biophysics and Biochemistry, Howard Hughes Medical Institute, Yale University, Boyer Center \\ for Molecular Medicine, New Haven, Connecticut 06536-0812 USA
}

\begin{abstract}
Psoralen cross-linking experiments in HeLa cell nuclear extracts have revealed the binding of U1 snRNA to substrates containing the SV40 late and adenovirus L3 polyadenylation signals. The sites of U1 cross-linking to the substrates map different distances upstream of the AAUAAA sequence to regions with limited complementarity to the $5^{\prime}$ end of U1 snRNA. U1 cross-linking to the same site in the SV40 late pre-mRNA is enhanced by the addition of an upstream $3^{\prime}$ splice site, which also enhances polyadenylation. Examination of different nuclear extracts reveals a correlation between $\mathrm{U} 1$ cross-linking and the coupling of splicing and polyadenylation, suggesting that the U1 snRNP participates in the coordination of these two RNA-processing events. Mutational analyses demonstrate that U1/substrate association cannot be too strong for coupling to occur and suggest that the U1 snRNP plays a similar role in recognition of internal and $3^{\prime}$ terminal exons. Possible mechanisms for communication between the splicing and polyadenylation machineries are discussed, as well as how interaction of the U1 snRNP with $3^{\prime}$ terminal exons might contribute to mRNA export.
\end{abstract}

[Key Words: Ul snRNP; polyadenylation; splicing; cross-linking]

Received July 27, 1992; revised version accepted February 8, 1993.

RNA-processing events in mammalian cells are highly regulated to ensure appropriate and accurate gene expression. A pre-mRNA must be spliced to remove all introns, it must be polyadenylated, and then, only after processing is complete, the message must be transported to the cytoplasm (see Izaurralde and Mattaj 1992). The premRNA signals and interacting factors that control splicing (see Green 1991; Guthrie 1991) and polyadenylation (see Wahle and Keller 1992) have been studied intensively, but the mechanism of mRNA transport and the links between the two processing events and export have remained elusive.

In splicing, conserved intron sequences at the 5' splice site, the $3^{\prime}$ splice site, and the branchpoint are critical. The trans-acting factors that recognize these sequences include U1, U2, U5, and U4/U6 small nuclear ribonucleoproteins (snRNPs), as well as a multitude of protein factors (for review, see Green 1991). The U1 snRNP has been considered to interact primarily with the $5^{\prime}$ splice site (Steitz et al. 1988), but recent data suggest that it also binds directly or indirectly at or near the branchpoint region, independent of other snRNPs: Interaction with the $3^{\prime}$ end of the intron has been suggested by analyses of spliceosome formation (Zillman et al. 1987; Ruby and Abelson 1988; Seraphin and Rosbash 1989; Barabino et al. 1990; Michaud and Reed 1991), by RNase T1 protection studies (Fu and Maniatis 1992), as well as by

\footnotetext{
${ }^{1}$ Present address: Department of Anatomy, University of California at San Francisco, San Francisco, California 94143-0452.

${ }^{2}$ Corresponding author.
}

genetic suppression studies (Reich et al. 1992). Also, the exon definition model suggests that in multiple intron substrates the U1 snRNP may interact with the upstream $3^{\prime}$ splice site across the exon (Robberson et al. 1990; Grabowski et al. 1991; Kuo et al. 1991). Thus, the U1 snRNP appears to play multiple roles during splicing and is clearly doing more than simply base-pairing with the $5^{\prime}$ splice site.

For polyadenylation, a very highly conserved signal, the hexanucleotide sequence AAUAAA, as well as a number of less well-conserved sequence elements found at varying distances upstream or downstream of the processing site, are present in the pre-mRNA (for review, see Wahle and Keller 1992). Fractionation studies have identified multiple factors required for cleavage and subsequent poly(A) addition, and it appears that (1) despite early hints of snRNP participation, no snRNP is required for in vitro polyadenylation; and (2) polyadenylation factors are distinct from splicing factors (see Wahle and Keller 1992). Moreover, polyadenylation and splicing can occur efficiently in vitro in the absence of one another (Krainer et al. 1984; Moore and Sharp 1984; 1985).

Although these results support the notion that splicing and polyadenylation proceed independently, several observations suggest that the two processes are intrinsically coupled. In vertebrate cells, most gene transcripts are both spliced and polyadenylated; and although some pre-mRNAs are polyadenylated without being spliced, there are no examples of mRNAs that are spliced but not polyadenylated. Histone pre-mRNAs, which are neither spliced nor polyadenylated, acquire their $3^{\prime}$ ends by a 
unique mechanism (Birnstiel and Schaufele 1988; Mowry and Steitz 1988); however, introduction of an intron into a histone pre-mRNA induces the use of a cryptic polyadenylation site suggesting an interaction between splicing and polyadenylation (Pandey et al. 1990). In addition, in vivo gene expression is enhanced by the insertion of an intron upstream of a polyadenylation signal (Buchman and Berg 1988) by increasing the level of poly $(A)^{+}$RNA (Huang and Gorman 1990). Enhancement of polyadenylation activity by the presence of upstream splicing signals (Niwa et al. 1990), as well as the reciprocal stimulation of splicing by polyadenylation (Niwa and Berget 1991), has also been observed in vitro.

Psoralen cross-linking is a powerful tool for characterizing RNA-RNA interactions. Here, using psoralen cross-linking, we show that the U1 snRNP binds to polyadenylation substrates and that this binding is enhanced by the presence of upstream splicing signals. The stimulation of Ul cross-linking correlates with the enhancement of polyadenylation activity and the behavior of substrates mutated at the site of $U 1$ interaction provide further information that, together, suggest a role for the Ul snRNP in the coupling of splicing and polyadenylation.

\section{Results}

\section{Polyadenylation substrates cross-link to U1 snRNA}

Using psoralen cross-linking, we set out to ask whether a small nuclear RNA (snRNA) interacts with polyadenylation substrates. Radiolabeled substrates containing the
SV40 late or adenovirus L3 polyadenylation signal were incubated in nuclear extract under poly|A) addition (Fig. 1A) or polyadenylation cleavage (Fig. 1B) conditions followed by the addition of psoralen and irradiation with $365 \mathrm{~nm}$ light on ice. Psoralen can intercalate into helical regions of RNA or DNA and, upon irradiation, can covalently cross-link the two strands together, thus identifying closely associated RNA sequences (Cimino et al. 1985|. Irradiated RNAs were isolated and immunoprecipitated with antibodies against the trimethylguanosine (TMG) cap of snRNAs to enrich for species cross-linked to snRNAs. When selected RNAs were fractionated on a denaturing gel, it was apparent that both the adenovirus L3 (Fig. 1A) and SV40 late (Fig. 1B) substrates became cross-linked to a TMG-capped RNA, as indicated by slowly migrating bands that were enriched by anti-TMG cap immunoprecipitation (Fig. 1A, cf. lanes 1 and 2; Fig. 1B, cf. lanes 1 and 3). Note that the cross-linked L3 RNA comigrates with poly $(\mathrm{A})^{+}$RNA generated during the reaction but that the selected cross-linked species is a tight band relative to the poly $\mid A)^{+}$RNA (Fig. 1A, lane 2, cf. lane 1). The profile and amount of cross-linking is the same using poly(A) addition or polyadenylation cleavage conditions (data not shown).

The identity of the snRNA cross-linked to the SV40 late and L3 polyadenylation substrates was determined next. First, the SV40 late cross-linked species were analyzed on two-dimensional gels in which the psoralen cross-links were photoreversed after the first dimension by irradiation with $254 \mathrm{~nm}$ light (Cimino et al. 1985). In such experiments, unlabeled substrate is cross-linked and selected with anti-TMG; all selected RNAs are then
Figure 1. Identification of psoralen crosslinks between polyadenylation substrates and the U1 snRNA. Adenovirus L3 $|A|$, SV40 late, or histone $H 3(B)$ substrates were incubated in nuclear extract under standard poly $(\mathrm{A})$ addition $(A)$ or standard polyadenylation cleavage $(B)$ conditions for $10 \mathrm{~min}$ before the addition of psoralen and cross-linking. Irradiated RNAs were immunoprecipitated with anti-TMG capantibodies, followed by RNase $\mathrm{H}$ treatment and fractionation on a $6 \%$ acrylamide/7 M urea gel. (A) Adenovirus L3 polyadenylation substrates containing a wildtype \{lanes 1-3\} or mutant (lanes 4-6) hexanucleotide sequence were examined. RNase $\mathrm{H}$ digestion was done in the presence of U1L2 (lanes 3,5) or no (lanes 2,4 ) oligonucleotide, and lanes 1 and 6 contain unselected irradiated RNA, which is onefiftieth the amount of RNA used for the selection of the other samples. $(B)$ Crosslinked, selected SV40 late polyadenylation substrate (lanes 1-4) or H3 substrate (lanes $5-8 \mid$ is shown after digestion with RNase contain irradiated RNA that was not immunoprecipitated or RNase $\mathrm{H}$ treated; lanes 2 and 6 contain RNA after incubation that was not irradiated, selected, or RNase $\mathrm{H}$ treated. Samples in lanes 1,2,5, and 6 are one-fiftieth the amount of RNA used for the selection of the other samples. The sizes of labeled DNA fragments used as markers are shown.

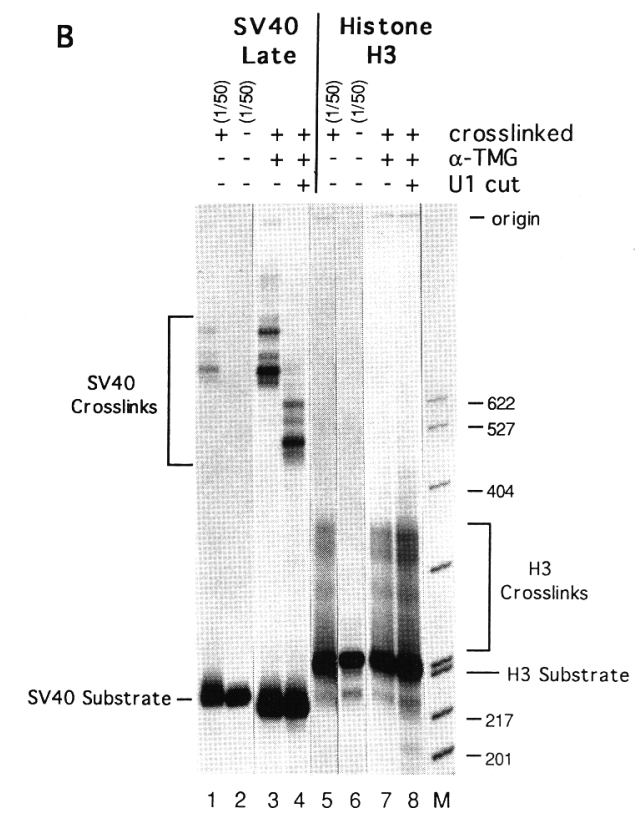

A

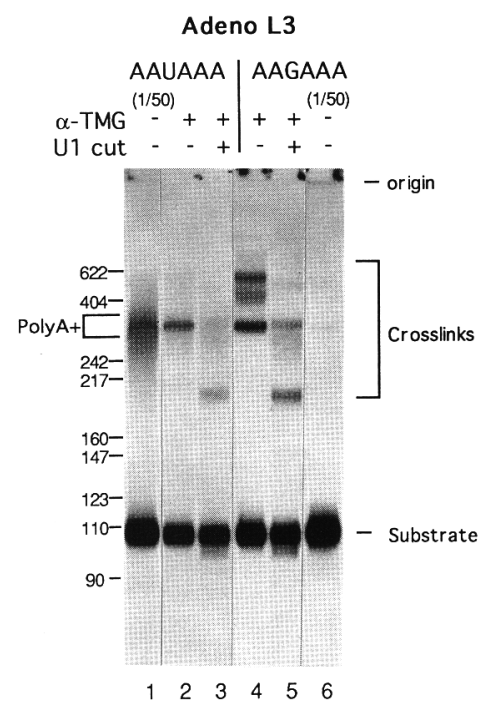


$3^{\prime}$-end-labeled with $\left[{ }^{32} \mathrm{P}\right]-\mathrm{pCp}$ and RNA ligase. Upon fractionation, RNAs cross-linked to each other run together in the first dimension but migrate true to size vertical to one another in the second dimension. The size of the RNA cross-linked to the SV40 late substrate surprisingly indicated that it might be Ul snRNA; this was confirmed by Northern blot analysis of a two-dimensional gel (data not shown).

RNase $\mathrm{H}$ analyses were performed to ask whether the adenovirus L3 substrate cross-link is also to U1 snRNA and to extend the characterization of the SV40 late crosslinks. An oligonucleotide complementary to nucleotides 64-75 in U1 (U1L2) was used to target cleavage of antiTMG-selected, cross-linked RNAs. This treatment selectively shifted both the multiple SV40 late and L3 cross-linked bands, indicating that U1 snRNA was crosslinked to both of these substrates (Fig. 1A, lane 3; Fig. 1B, lane 4). In contrast, RNase $\mathrm{H}$ alone (Fig. 1A, lane 2; Fig. 1B, lane 3) or control oligonucleotides (data not shown) had no effect. As control, a mouse histone pre-mRNA substrate $(\mathrm{H} 3$; Fig. 1B, lanes $5-8)$ was tested and did not yield any apparent cross-links that were shifted by U1 cutting (Fig. 1B, lane 7, cf. lane 8), indicating that none of the cross-linked species contain U1 snRNA. A precursor rRNA substrate containing the early processing site (Craig et al. 1987) likewise gave negative results (data not shown).

To determine whether active polyadenylation is required for U1 snRNA cross-linking, mutant substrates were examined. The point mutant AAUAAA $\rightarrow$ AAGAAA in the L3 substrate abolishes specific polyadenylation, as well as polyadenylation complex formation (Skolnik-David et al. 1987; data not shown). As shown in Figure 1A, lane 4, the psoralen cross-linking profile of the mutant changes to include more crosslinked species; all are shifted by the oligonucleotide-targeted degradation of U1 (lane 5). We conclude that there is a difference in the accessibility of mutant and wildtype polyadenylation substrates to the Ul snRNP. Yet, quantitation of several such experiments indicated that the efficiency of formation of the fastest migrating crosslinked species of the mutant is comparable to that for the corresponding cross-link on the wild-type substrate. Likewise, analyses of U1 cross-linking to SV40 late substrates containing downstream deletions that decrease polyadenylation in vitro (Zarkower and Wickens 1988) showed no difference in either the cross-linking profile or efficiency (data not shown).

Because the $5^{\prime}$ end of Ul snRNA is involved in the recognition of 5 ' splice sites, we asked whether it might also be responsible for U1 cross-linking to polyadenylation substrates. A $2^{\prime}$-O-methyloligoribonucleotide $\left\{2^{\prime}-\mathrm{O}\right.$ $\mathrm{Mel}$ (Sproat et al. 1989) complementary to nucleotides 1-14 of the U1 snRNA $\left(U 1_{1-14}\right)$ was added to nuclear extract before incubation with substrate and subsequent psoralen cross-linking. The appearance of cross-linked species for both the L3 and SV40 late substrates was blocked (Fig. 2A,B), whereas the cross-linking profile of a control substrate, H3, was unaffected (Fig. 2C). A nonspecific oligonucleotide had little or no effect even at the highest concentration (Fig. 2A,B, cf. lanes 2-5 with 6-9), whereas an oligonucleotide complementary to only nucleotides 1-10 of U1 snRNA was likewise able to block cross-linking (data not shown). These experiments were done using polyadenylation cleavage conditions (containing $3^{\prime}$ deoxy-ATP) so that the L3 poly(A) ${ }^{+}$RNA did not comigrate with the cross-linked RNA. Therefore, anti-TMG selection was not necessary to visualize the cross-linked species, and we could estimate from Figure 2, A and B, that $1-5 \%$ of the input L3, as well as SV40 late substrate, became cross-linked to U1, probably via base-pairing with the $5^{\prime}$ end of the U1 RNA. Figure 2, A and $B$, also shows that the appearance of Ul cross-linking to the L3 and SV40 late substrates is dependent on the addition of nuclear extract (lanes 11), psoralen (lanes 10), and irradiation (lanes 13) as expected for a psoralen cross-link. The U1/substrate cross-links are also able to be photoreversed with UV light, releasing uncross-linked RNAs that can be visualized in two-dimensional gel analyses \{data not shown, but see Fig. 5, below\}, a unique property of psoralen cross-links. The cross-linked species generated in an S-100 extract, which contains an approximately equal concentration of U1 snRNPs, are similar to those in a nuclear extract (lanes 12); but the level of U1-specific cross-links is dramatically reduced. S-100 extract is not competent for polyadenylation, indicating that the Ul/substrate interaction is significantly enhanced in an active polyadenylation extract.

\section{U1 snRNA binds upstream of the hexanucleotide signal}

To localize the region of the substrates to which U1 snRNA was cross-linked, RNase $\mathrm{H}$ mapping was performed. The U1/substrate cross-linked species were first gel purified and then treated with RNase $\mathrm{H}$ in the presence of deoxyoligonucleotides complementary to different regions of each substrate. Digestion yields two substrate fragments: One does not contain the cross-linked U1 RNA and runs true to size on a denaturing gel; the other is shifted in the gel because of the presence of the cross-link. It is therefore possible to determine whether the fragment $3^{\prime}$ or $5^{\prime}$ of the cleavage site contains the cross-link and, in this way, to narrow down the site of interaction.

Figure 3 shows a mapping experiment comparing the two most prominent U1/SV40 late cross-linked species: U1/SVL upper and U1/SVL lower. RNase $\mathrm{H}$ cleavage of both of these cross-linked species (Fig. 3, lanes 4, 7), using the SV-A oligonucleotide compared with the uncross-linked control (lane 1), reveals that the $3^{\prime}$ fragment is shifted in the gel indicating that the cross-links are $3^{\prime}$ of the cleavage site using the SV-A oligonucleotide. Alternatively, RNase $\mathrm{H}$ cleavage with the SV-B or SV-D oligonucleotide results in shifted $5^{\prime}$ fragments (for SV-B, cf. lane 2 with 5 and 8 ; for SV-D, data not shown), indicating that the cross-links are $5^{\prime}$ of these cleavage sites. Similarly, for the adenovirus L3 substrate, the site of $U 1$ cross-linking was mapped between two oligonucleotides, L3-A and L3-B (data not shown). The regions tar- 
A

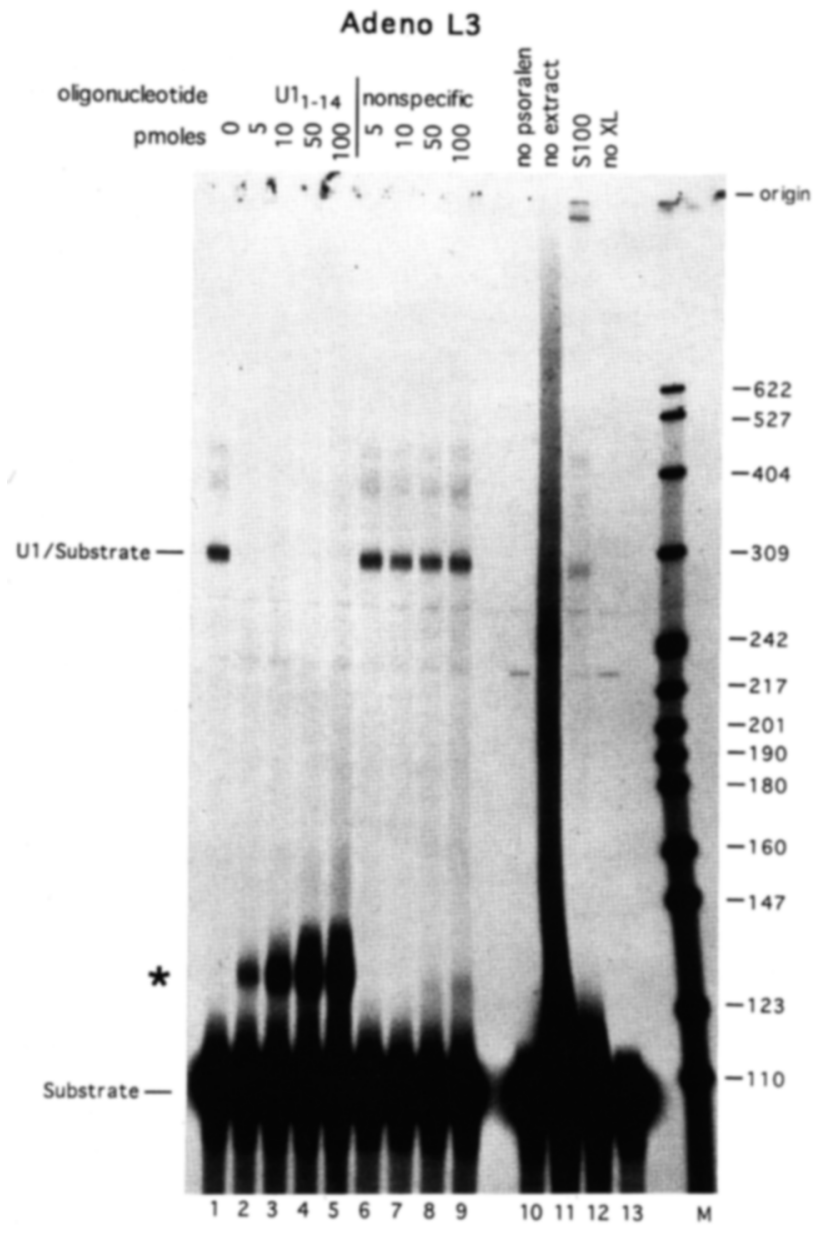

B

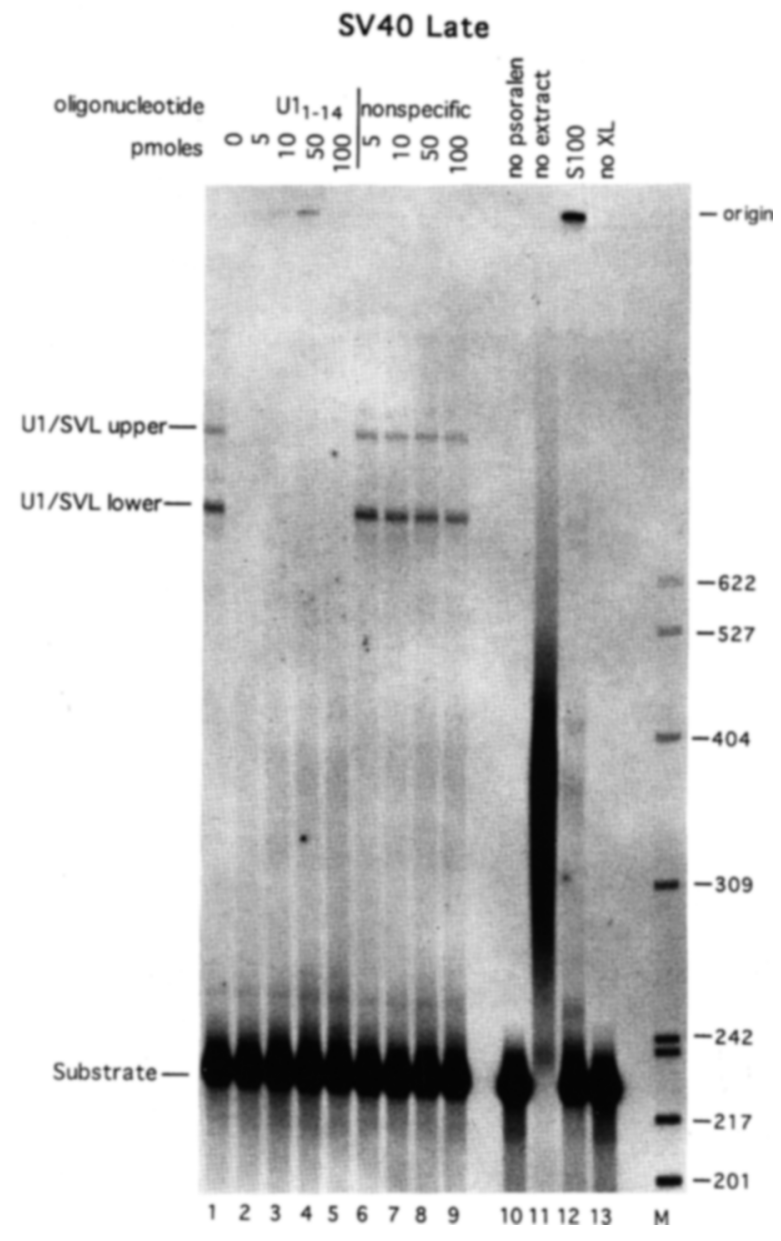

C

Figure 2. The U1 snRNA/substrate cross-links are specifically blocked with the $\mathrm{Ul}_{1-14} 2$ '-O-Me oligonucleotide. Standard polyadenylation cleavage reactions containing increasing concentrations of a 2'-OMe oligonucleotide were incubated at $30^{\circ} \mathrm{C}$ for $10 \mathrm{~min}$. Samples were then cross-linked as described in Materials and methods and fractionated on a $6 \%$ acrylamide $/ 7 \mathrm{M}$ urea gel. Adenovirus L3 $(A)$, SV40 late $\left(B \mid\right.$, and $\mathrm{H} 3\langle C|$ substrates were examined. In $A$ and $B$, lanes 2-5 contain the $\mathrm{Ul}_{1-14} 2^{\prime}$-O-Me oligonucleotide; lanes 6-9 contain a nonspecific 2'-O-Me oligonucleotide; and lanes 1 and 10-13 do not contain an oligonucleotide. The amount of each oligonucleotide is indicated at the top of each lane: 5 (lanes 2,6), 10 (lanes 3,7), 50 (lanes 4,8), and 100 pmoles $/ 25 \mu$ ) reaction (lanes 5,9). These amounts are in excess of the estimated levels of Ul snRNP and input substrate. Note that with the L3 substrate $|A|$, the addition of $\mathrm{Ul}_{1-14} 2^{\prime}-\mathrm{O}-\mathrm{Me}$ oligonucleotide leads to the appearance of an additional, abundant cross-linked species [asterisk $\left.\left.\right|^{*}\right)$ ]. Its location in the gel and pattern of generation suggest that it is either an efficient internal substrate cross-link brought about by the presence of the oligonucleotide or the substrate cross-linked directly to the oligonucleotide. Samples treated under different conditions are shown (lanes 10-13). Lanes 10 were irradiated in the absence of psoralen, lanes 11 had no added nuclear extract, lanes 12 contained S-100 extract instead of nuclear extract, and lanes 13 were not irradiated. Note that in the absence of nuclear extract (lanes 13), many internal cross-links are seen as indicated by the large smear throughout. In $C, 100$ pmoles $/ 25 \mu 1$ reaction of the $\mathrm{Ul}_{1-14} 2^{\prime}$-O-Me oligonucleotide (lane 1) or the nonspecific $2^{\prime}-\mathrm{O}-\mathrm{Me}$ oligonucleotide (lane 2) was used. Lanes M contain labeled MspI-digested pBR322 fragments.

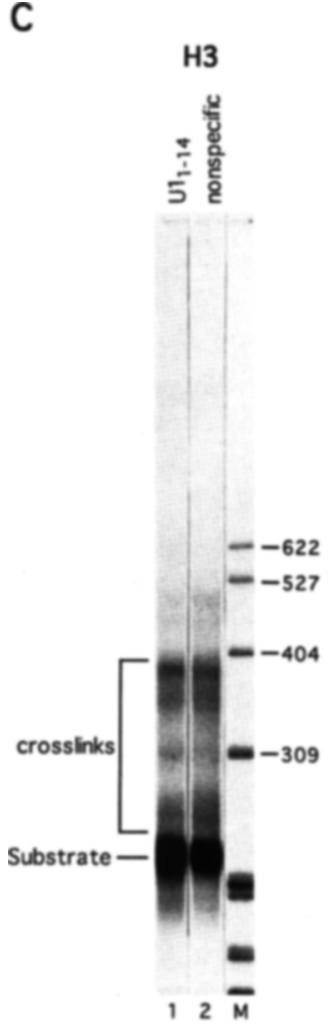




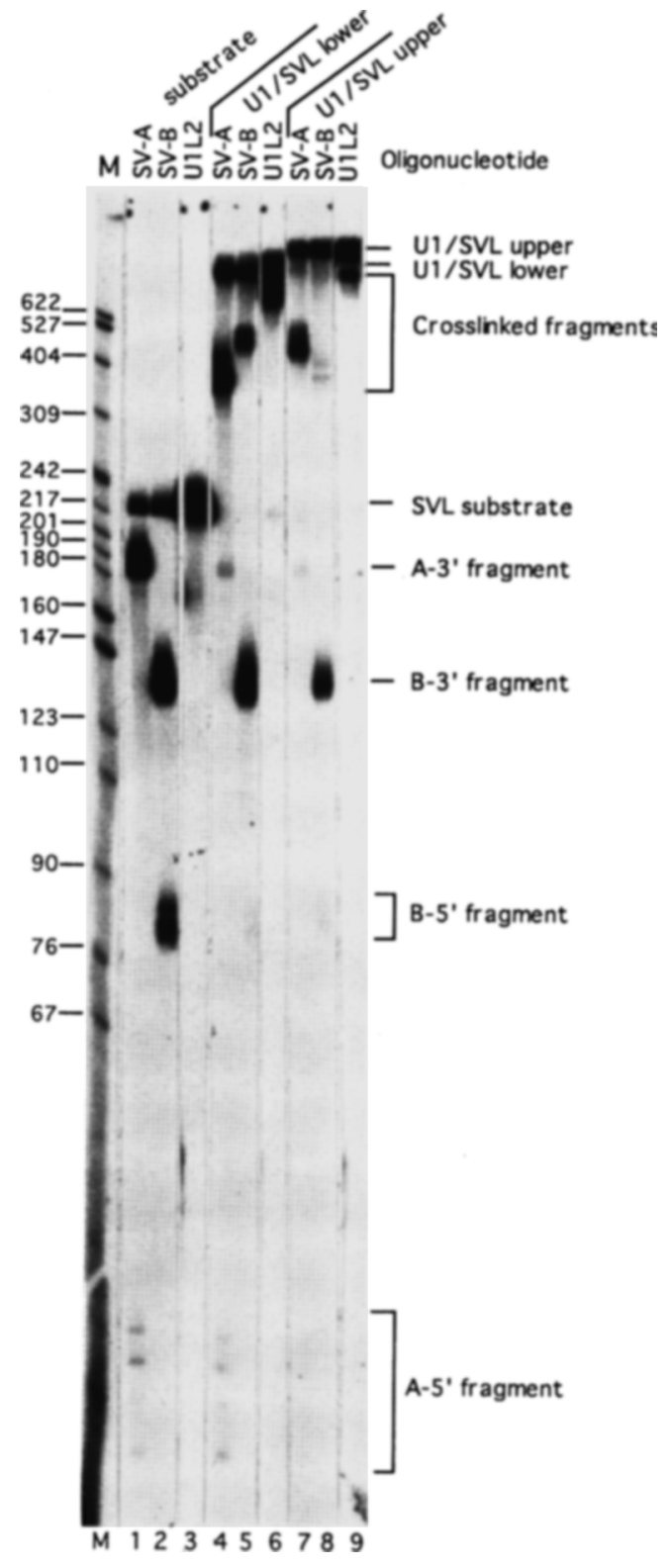

Figure 3. RNase $\mathrm{H}$ mapping of the $\mathrm{Ul}$ cross-linking site on the SV40 late substrate. RNAs from an irradiated standard polyadenylation cleavage reaction were gel purified, digested with RNase $\mathrm{H}$, as described in Materials and methods, and fractionated on a $10 \%$ acrylamide $/ 7 \mathrm{M}$ urea gel. The starting RNAs were SV40 late substrate (lanes 1-3), U1/SVL lower (lanes 4-6), or U1/SVL upper (lanes 7-9). RNase H digestion was done in the presence of the SV-A (lanes 1,4,7), SV-B (lanes 2,5,8), or U1L2 (lanes $3,6,9$ ) oligonucleotides. The $5^{\prime}$ and $3^{\prime}$ fragments generated by specific RNase $\mathrm{H}$ cleavage with each oligonucleotide are indicated. Lane $M$ contains kinased MspI-digested pBR322 fragments.

geted by these complementary oligonucleotides on the SV40 late and L3 substrates are shown in Figure 4, A and $B$.

To map precisely the sites of cross-linking in the SV40 late and L3 substrates, another strategy was employed.
U1/substrate cross-linked RNAs were gel purified, digested with RNase T1, and fractionated on a two-dimensional gel in which the psoralen cross-links were photoreversed between the two dimensions. As described above, uncross-linked fragments will migrate on a diagonal; any cross-linked oligonucleotide will run differently in the two dimensions, and the second dimension will reveal the size of the $\mathrm{T} 1$ fragment from the substrate that had contained the cross-link. Because only the substrate is labeled, one band is expected but two are normally seen (D. Wassarman and Steitz 1992). This is because the photoreversal is not $100 \%$ efficient and the upper species represents a $\mathrm{T} 1$ fragment containing a psoralen monoadduct, whereas the lower band is the unmodified T1 fragment. Accordingly, for the U1/SVL lower species (Fig. 5A), two spots run off the diagonal, with the smaller indicating that the U1 cross-link to the SV40 late substrate lies within a 5 nucleotide T1 fragment. Analysis of the U1/SVL upper species (data not shown/gave rise to the same two spots in addition to a set of four fragments consistent with the presence of the same U1/substrate cross-link as well as an intramolecular substrate cross-link. For the U1/L3 cross-link /Fig. 5B), two pairs of Tl fragments are observed. One pair is seen also when the substrate region of the gel fractionating the cross-linked reaction is analyzed (data not shown); it is therefore not specific to the U1/L3 crosslinked species. The T1 fragments marked by arrows are uniquely present in the U1/L3 cross-linked band and show that U1 cross-links to a 4-nucleotide Tl fragment in the L3 substrate.

As shown in Figure 4A, there are two adjacent 5-nucleotide T1 fragments in the SV40 late substrate that lie between the regions complementary to oligonucleotides SV-A and SV-B. Thus, the Ul cross-link may be found in either of these T1 fragments. In the L3 substrate there is a unique 4-nucleotide $\mathrm{Tl}$ fragment that lies between the regions complementary to oligonucleotides L3-A and L3-B to which Ul snRNA must be cross-linked (Fig. 4B). The T1 fragments from both the SV40 late and L3 substrates are within areas of potential base-pairing with the 5' end of U1 snRNA and are consistent with known requirements for psoralen intercalation and cross-linking (Cimino et al. 1985). Although these results are consistent with cross-linking to the $5^{\prime}$ end of Ul snRNA, the actual site of cross-linking in $\mathrm{U} 1$ is unknown. However, because the cross-linking can be blocked by sequestering the $5^{\prime}$ end of U1 (Fig. 2A,B) and U1 cross-linking responds to substrate mutants disrupting or increasing the potential for base-pairing (see below), it appears that the primary interaction is between the $5^{\prime}$ end of $\mathrm{Ul}$ and the substrate.

The T1 fragment from the L3 substrate includes the junction between the $\mathrm{L} 3$ and vector sequences, although most of the base-pairing potential with U1 snRNA lies within the L3 sequence. The actual L3 sequence in this region is shown in Figure 4C. An L3 polyadenylation substrate containing additional viral upstream sequences was examined and also found to form a crosslink that is selected with anti-TMG antibodies and its 
A

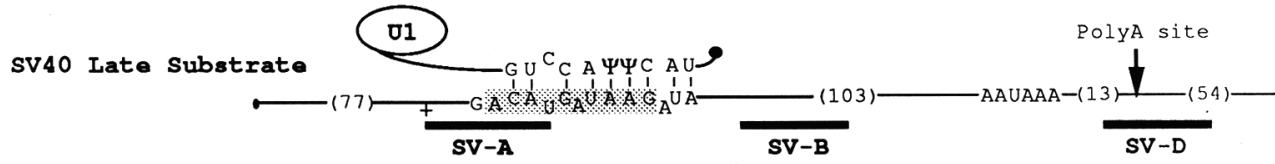

B

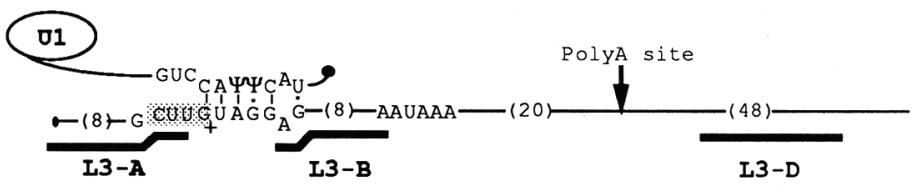

C

Adeno I3 Sequence

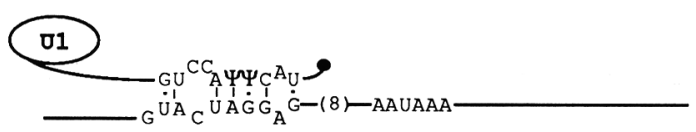

D

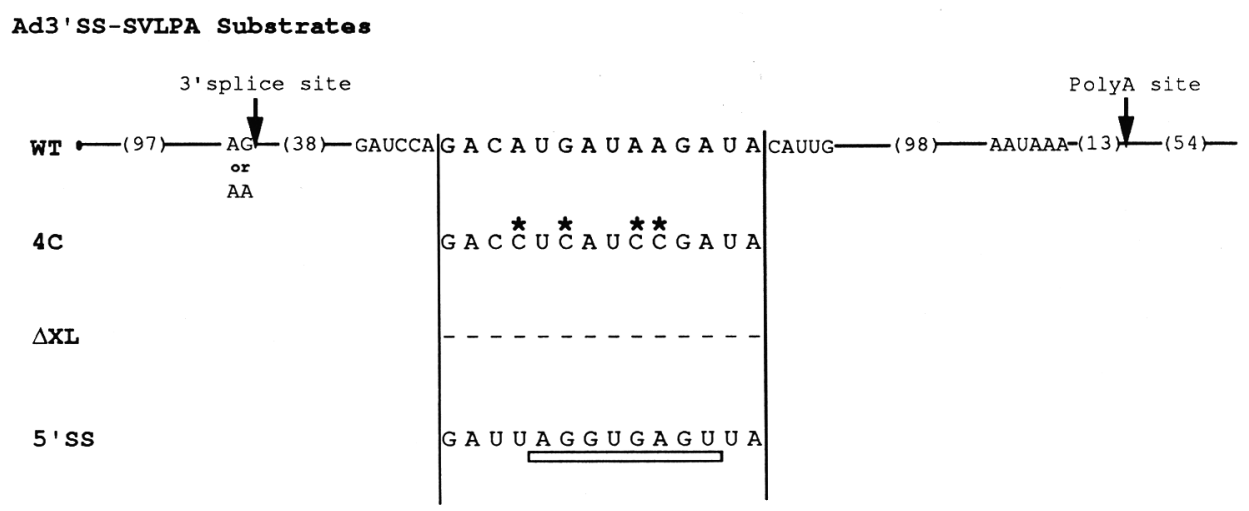

Figure 4. Potential base-pairing interactions between Ul snRNA and polyadenylation substrates. The SV40 late $(A)$ and adenovirus L3 $(B)$ substrates are diagramed to show potential base-pairing with the $5^{\prime}$ end of Ul snRNA. The RNase Tl fragments that contained the cross-link are shown in shaded boxes. The thick lines below the substrates mark regions complementary to the oligonucleotides used in RNase $\mathrm{H}$ mapping experiments. The junctions between viral and vector sequences in the substrates are marked by a plus sign $\left\{+\mid\right.$. The bold dots at the $5^{\prime}$ ends of the substrates and U1 RNAs represent the GpppG and TMG cap-structures, respectively. $(C)$ The potential Ul snRNA base-pairing to the native adenovirus L3 sequence including additional upstream nucleotides not present in the L3 substrate is shown. $\{D \mid$ The Ad3'SS-SVLPA wild-type and mutant substrates are diagramed. The 4C substrates have four bases changed to cytosines [indicated by asterisks $\left(^{*}\right)$, the $\Delta \mathrm{XL}$ substrates have a 14-nucleotide deletion (nucleotides deleted indicated by -1 , and the 5 'SS substrates have a 10 nucleotide replacement, which includes a consensus 5 ' splice site sequence /underlined by a long open rectangle).

appearance specifically blocked with the $\mathrm{U}_{1-14} 2^{\prime}-\mathrm{O}-\mathrm{Me}$ oligonucleotide, consistent with cross-linking to Ul snRNA (data not shown). The sites of Ul cross-linking in both substrates are upstream of the hexanucleotide signal, although the distance is much greater for the SV40 late substrate (106 nucleotides) than the L3 substrate (14 nucleotides), and do not coincide with any previously identified upstream sequences involved in polyadenylation (see Wahle and Keller 1992).

\section{U1 snRNA shows enhanced cross-linking to coupled substrates}

Because the U1 snRNP is clearly involved in splicing but also appears to bind upstream of polyadenylation sites, we then examined the cross-linking of $U 1$ to substrates that contain signals necessary for both processes. Ad3'SS-SVLPA has a 3' splice site from the adenovirus major late transcript and 82 nucleotides of preceding intron sequence followed by the SV40 late polyadenylation signal. It contains the same SV40 sequences as the uncoupled SV40 late substrate used above. A substrate similar to Ad3'SS-SVLPA was reported previously to couple splicing and polyadenylation in vitro (Niwa et al. 1990).

Figure 6 shows that U1 snRNA cross-links to the coupled substrate (lane 8 ) at a level three- to fivefold above cross-linking to the mutant substrate (lane 1). Blocking the $5^{\prime}$ end of U1 snRNA with the $\mathrm{Ul}_{1-14} 2^{\prime}$-O-Me oligonucleotide specifically abolishes the appearance of the major cross-linked species (cf. lanes 2-4 and 9-11 with 5-7 and 12-14, containing a nonspecific oligonucleotide), as with the uncoupled SV40 late substrate (Fig. 2). RNase H mapping of both the wild-type and mutant U1/ Ad3'SS-SVLPA cross-links again localized the site of cross-linking between the regions complementary to the SV-A and SV-B oligonucleotides (data not shown), indicating that the site of U1 snRNA interaction is the same 

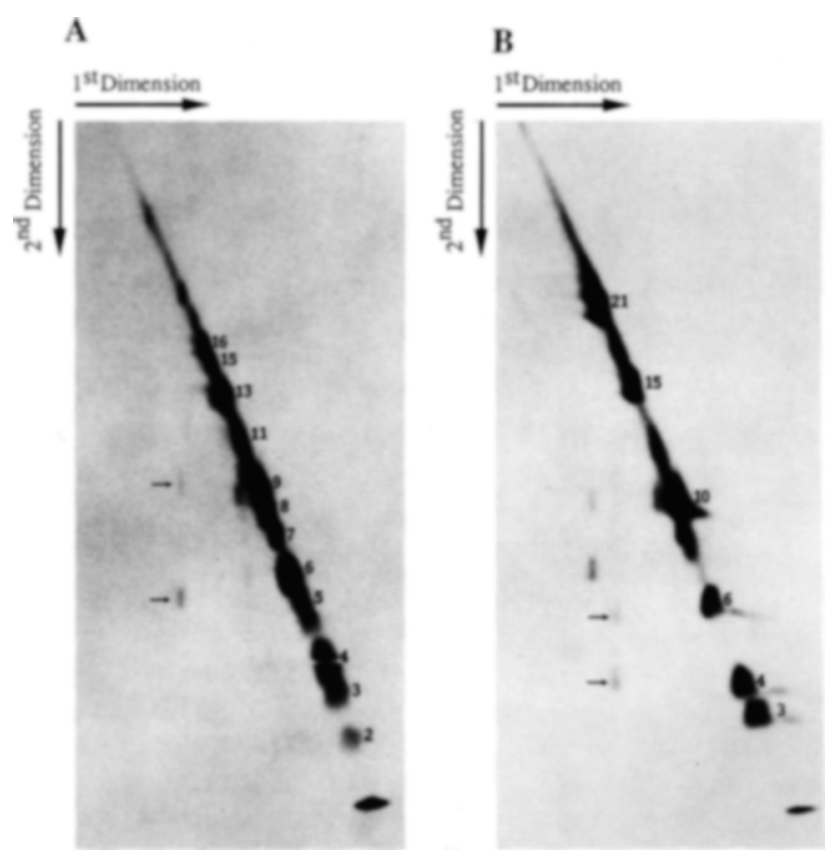

Figure 5. Mapping the site of $\mathrm{Ul}$ cross-linking in the substrates to RNase T1 fragments. Gel-purified U1/SVL lower $(A)$ or U1/L3 (B) cross-links were digested with RNase T1 and fractionated on two-dimensional gels containing $20 \%$ acrylamide $/ 7$ $M$ urea as described in Materials and methods. The SV40 late substrate was labeled with $\left[\alpha^{32} \mathrm{P}\right]$ UTP at high specific activity and $\left[\alpha^{32} \mathrm{P}\right]$ ATP at low specific activity. The sizes of the T1 fragments are shown on the diagonal and were determined by comparison on a one-dimensional gel to markers (data not shown/ and from the length and relative labeling intensities of the fragments predicted to be generated by RNase $T 1$ digestion. Arrows mark the RNase T1 fragments generated by photoreversal that had been cross-linked to the Ul snRNA.

as with the uncoupled SV40 late polyadenylation substrate.

To ask whether binding of the Ul snRNP to the premRNA is essential for communication between splicing and polyadenylation, we attempted to assay polyadenylation of the coupled transcript in nuclear extracts in which the $5^{\prime}$ end of Ul snRNA had been blocked with a 2'-O-Me oligonucleotide or ablated by RNase $\mathrm{H}$. Unfortunately, we found that the addition of nonspecific oligonucleotides (as well as the Ul-specific oligonucleotide) inhibited the enhancement of polyadenylation observed with the wild-type relative to the mutant-coupled transcript under standard poly $(\mathrm{A})$ addition or cleavage conditions, as well as optimized conditions (see Materials and methods) for coupled activity (data not shown). Even preincubation of the nuclear extract without added oligonucleotide was sufficient to abolish the coupling of splicing and polyadenylation, although little effect on general polyadenylation activity was seen /data not shown). The amount of U1 cross-linking observed was also reduced under these conditions although not totally abolished (data not shown), suggesting a correlation be- tween the level of U1 snRNA/substrate cross-linking and the coupling of polyadenylation and splicing.

Because the coupling of splicing and polyadenylation has been reported to be extract dependent (Niwa et al. 1990), we screened several nuclear extracts to assess U1 snRNA cross-linking relative to the enhancement of polyadenylation activity by a wild-type $3^{\prime}$ splice site sequence (Fig. 7). Of many nuclear extracts tested, all but one (extract $C$ in Fig. 7) showed at least twofold enhancement of polyadenylation cleavage activity and a three- to fivefold increase in U1 cross-linking (Fig. 7, A and B, compare odd- with even-numbered lanes/ with the Ad3'SS-SVLPA containing the wild-type $3^{\prime}$ splice site compared with the mutant $3^{\prime}$ splice site. Nuclear extract $\mathrm{C}$ showed equal polyadenylation cleavage activity with the 3' splice site wild-type and mutant substrates (Fig. $7 \mathrm{~A}$, lanes 5,6$)$ and a markedly lower level of U1 crosslinking (Fig. 7B, cf. lanes $1-4$ with 5,6 ). Nonetheless, nuclear extract $C$ was quite active in general polyadenylation as assessed on the Ad3'SS(AA)-SVLPA substrate (Fig. 7A, cf. lane 5 with 1 and 3) and on the uncoupled SV40 late substrate (data not shown). We conclude that there is a correlation between the level of Ul snRNA/

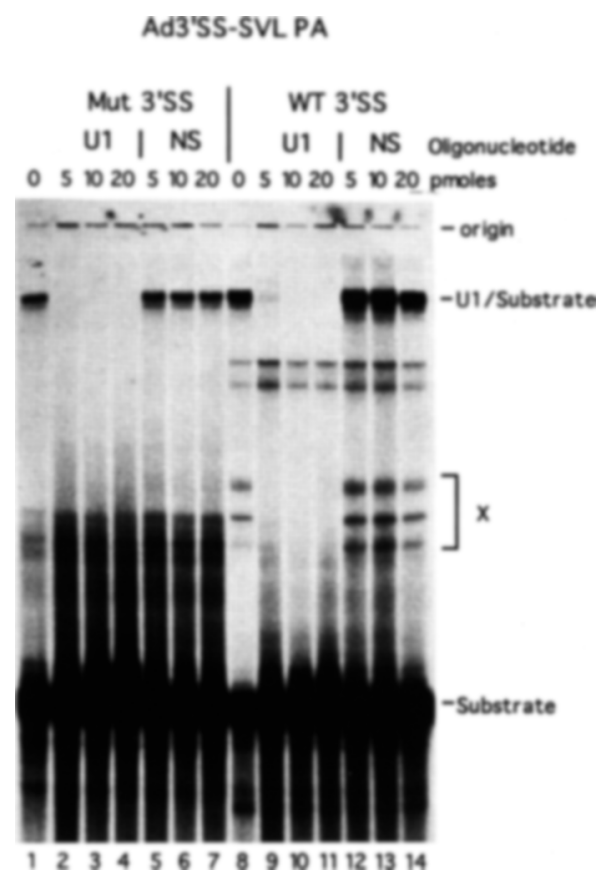

Figure 6. The U1/substrate cross-link is enhanced by an upstream splicing signal. Standard polyadenylation cleavage reactions were incubated for $10 \mathrm{~min}$ immediately after the addition of a $2^{\prime}$-O-Me oligonucleotide using the wild-type (lanes 8-14) or $3^{\prime}$ splice site mutant (lanes 1-7) Ad3'SS-SVLPA substrate followed by psoralen cross-linking as described in Materials and methods. Lanes 1 and 8 contain no oligonucleotide, lanes 2-4 and 9-11 contain the $\mathrm{U}_{1-14} 2^{\prime}$-O-Me oligonucleotide, and lanes 5-7 and 12-14 contain a nonspecific $2^{\prime}$-O-Me oligonucleotide (see Materials and methods). The concentrations of oligonucleotides per 25- $\mu$ l reaction are given. Results were quantitated on a PhosphorImager as described in Materials and methods. 
Figure 7. Correlation between U1 crosslinking and the coupling of splicing and polyadenylation in different nuclear extracts. Polyadenylation cleavage reactions (25 $\mu$ l) optimized for coupling activity (see Materials and methods) using three different HeLa cell nuclear extracts were incubated at $30^{\circ} \mathrm{C}$. After $10 \mathrm{~min}, 15 \mu \mathrm{l}$ aliquots were removed, psoralen cross-linked, and analyzed on a $5 \%$ acrylamide $/ 7 \mathrm{M}$ urea gel. The remainder of each sample was immediately returned to $30^{\circ} \mathrm{C}$ and incubated for an additional $20 \mathrm{~min}$ after which a $5 \mu \mathrm{l}$ aliquot was removed, RNA extracted, and fractionated on a $5 \%$ acrylamide $/ 7 \mathrm{M}$ urea gel to analyze the polyadenylation efficiency. Polyadenylation cleavage activity assayed in the presence of $3^{\prime}$ deoxy-ATP $|A|$ and cross-linking activity $(B)$ of nuclear extracts A (lanes 1,2), B (lanes 3,4), and C (lanes 5,6 ) using the Ad3'SS(AA)-SVLPA (lanes 1,3,5), or Ad3'SS|AG)-SVLPA (lanes $2,4,6)$ is shown. Results were quantitated on a PhosphorImager (see Materials and methods); comparable results to those shown with extracts A and B were observed with five other nuclear extracts. Lanes M contain 5'-end-labeled fragments from MspI digested pBR322.

substrate cross-linking and the enhancement of polyadenylation of a coupled substrate compared with an uncoupled substrate, independent of the general polyadenylation activity of the extract.

\section{Analysis of polyadenylation substrates mutated in the U1 interaction region}

Because we were unable to directly assess the involvement of the U1 snRNP in the coupling of splicing and polyadenylation, we then analyzed coupled substrates containing mutations in the region where U1 snRNA cross-links. These mutations were designed to specifically decrease or increase the potential base-pairing interaction between the substrate and the 5 ' end of the U1 snRNA and were made in the context of the wild-type and mutant $3^{\prime}$ splice site substrates. The sequences of the mutant substrates, shown in Figure 4D, are altered only in the region of $\mathrm{Ul}$ interaction (Fig. 4D). The Ad3'SS-SVLPA(4C) substrates contain 4 base changes from purines to cytosine that disrupt the potential basepairing with Ul. Note that the pyrimidines present in this region were not changed; because psoralen is known to cross-link pyrimidines, the potential for psoralen cross-linking of these substrates has not been drastically altered. The Ad3'SS-SVLPA $(\Delta \mathrm{XL})$ substrates have deleted the entire region of potential base-pairing to the $5^{\prime}$ end of U1. The Ad3'SS-SVLPA(5'SS) mutant replaces the same region with a consensus $5^{\prime}$ splice site sequence, thereby increasing the potential base-pairing with U1. Not shown in Figure $4 D$ is a hexanucleotide mutation (AAGAAA), which was also made in both the substrate containing a wild-type and mutant $3^{\prime}$ splice site.
B

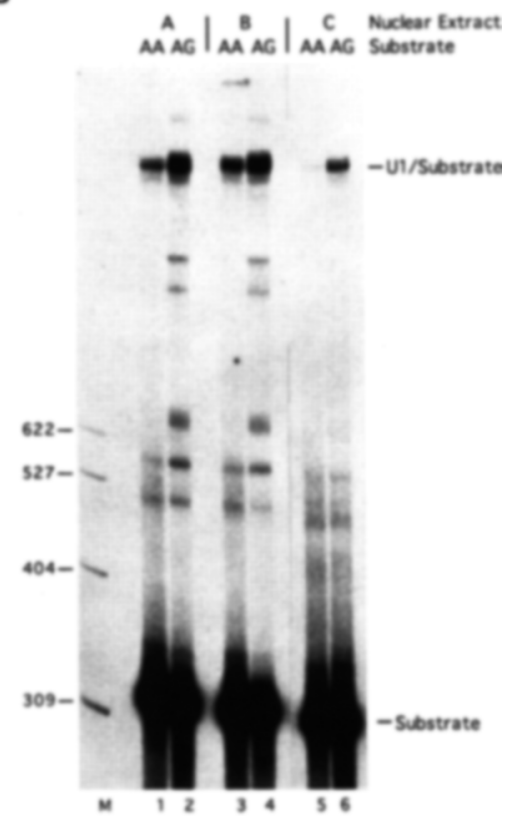

The mutant substrates were analyzed for poly $(A)$ addition, polyadenylation cleavage, and cross-linking activities (Fig. 8). As seen above, there is a clear enhancement of poly(A) addition ( 1.6 fold) and polyadenylation cleavage $(\sim 2.5$ fold $)$ activities with the control Ad3'SSSVLPA substrates containing a wild-type compared with the mutant $3^{\prime}$ splice site (Fig. 8A,B, cf. lanes 9 and 10 ). An equal relative enhancement is seen also with the Ad3'SS-SVLPA(4C) and Ad3'SS-SVLPA( $\triangle X L)$ substrates (lanes 4 vs. 3 ; lane 6 vs. 5 ). Note that the $\triangle X L$ substrates are shorter because of the deletion; therefore, the cleaved products are also shorter (lanes 5,6). Although the enhancement conferred by the wild-type $3^{\prime}$ splice site is small, especially in the poly(A) addition reactions, these experiments have been repeated several times and have yielded the same results consistently, indicating that the trends observed are significant. In contrast, neither the poly(A) addition nor cleavage level is sensitive to the $3^{\prime}$ splice site for the Ad3'SS-SVLPA $\left[5^{\prime}\right.$ 'SS $\}$ substrate with the consensus $5^{\prime}$ splice site sequence (Fig. 8A,B, lanes 8 vs. 7). The substrates containing the hexanucleotide mutant do not show poly(A) addition or cleavage activity as expected (Fig. 8A,B, lanes 1 and 2). [Note that arrowheads in Figure 8, A and B, denote a nonspecific degradation product (see figure legend).)

In parallel, the mutant substrates were tested for their ability to cross-link to U1 snRNA in nuclear extract. As predicted, Figure $8 \mathrm{C}$ reveals that the Ad3'SS-SVLPA $(4 \mathrm{C})$ and $(\triangle X L)$ substrates are decreased in Ul snRNA crosslinking (lanes 3-6) but retain their coupling; presumably, the residual cross-linking reflects continued association of the Ul snRNP with the substrate even though the complementary mRNA region has been mutated. In con- 
A

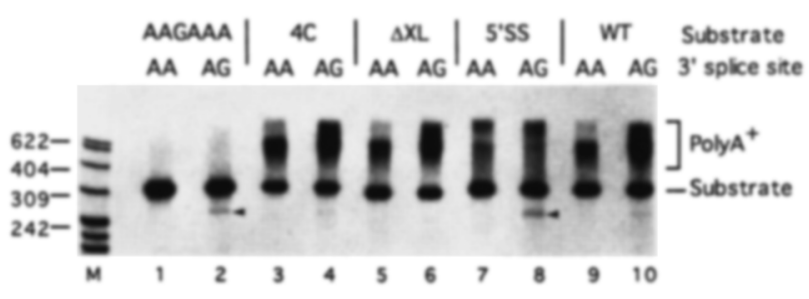

B

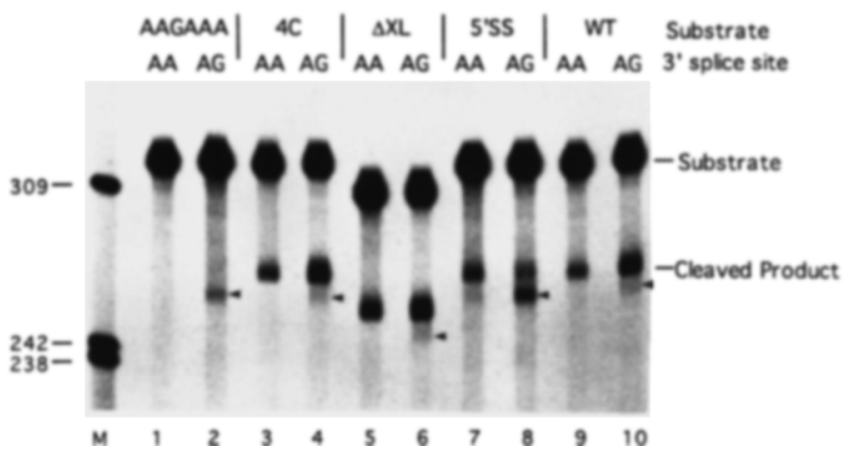

C

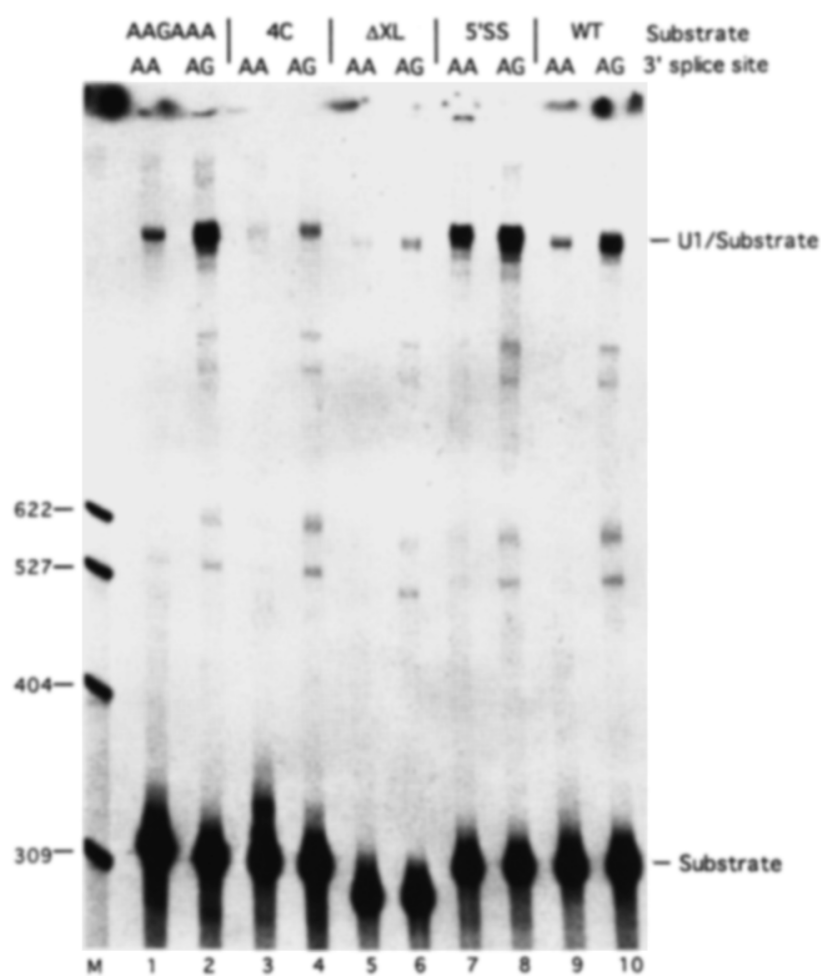

Figure 8. Mutations affecting the binding of UI snRNP to the coupled substrates also affect the coupling of polyadenylation and splicing. Poly $(\mathrm{A})$ addition $(A)$, polyadenylation cleavage $(B)$, and cross-linking $(C)$ activities were tested under conditions optimized for coupling (see Materials and methods) on multiple substrates: Ad3'SS-SVLPA(AAGAAA) (lanes 1,2), Ad3'SS-SVLPA(4C) (lanes 3,4), Ad3'SS-SVLPA| $\triangle X L$ ) (lanes 5,6), Ad3'SS-SVLPA(5'SS) (lanes 7,8), and Ad3'SS-SVLPA(WT) (lanes 9,10). Each substrate contained either a wild-type (lanes $2,4,6,8,10$ ) or mutant (lanes $1,3,5,7,9$ ) $3^{\prime}$ splice site as indicated. In $A$ and $B$, spurious bands (marked by arrowheads\} are present in addition to the polyadenylation products in all reactions with substrates containing a wild-type $3^{\prime}$ splice site and are most apparent with the Ad3'SS(AG)-SVLPA(5'SS) substrate (lane 8). Analyses of substrates containing additional vector sequences at their $3^{\prime}$ ends showed a shift of this band (with no effect on the polyadenylation product bands) indicating that it arises from shortening of the substrate at the $5^{\prime}$ end, rather than from polyadenylation cleavage (data not shown). Lanes $M$ contain $5^{\prime}$-endlabeled fragments from MspI digested pBR322.

trast, the Ad3'SS-SVLPA(5'SS) substrates increase their Ul snRNA cross-linking but show little difference in polyadenylation activity between the wild-type and mutant $3^{\prime}$ splice site (lanes 7,8 ). In the presence of the $\mathrm{Ul}_{1-14} 2^{\prime}$-O-Me oligonucleotide, the U1 snRNA crosslinks to all substrates were specifically abolished (data not shown).

\section{Discussion}

We have discovered that the U1 snRNP interacts with both SV40 late and adenovirus L3 polyadenylation substrates. The sites of Ul cross-linking map upstream but at different distances from the hexanucleotide sequence to regions that exhibit limited complementarity to the $5^{\prime}$ end of the U1 snRNA. The efficiency of U1 cross-linking increases upon the addition of an upstream 3 ' splice site, and the ability of a nuclear extract to couple splicing and polyadenylation correlates with the extent of cross-linking of U1 snRNA to polyadenylation substrates. Mutational analyses of the Ul cross-linking site in the cou- pled substrates argue that the Ul cross-linking we observe is an indicator of the level of Ul snRNP association and that the presence of the Ul snRNP correlates with the coupling of splicing and polyadenylation. In addition, the mutant data suggest that internal and 3'-terminal exons are recognized in a similar manner. Our results therefore provide evidence that the U1 snRNP is involved in communication between the splicing and polyadenylation machineries and add to the growing list of indications that $\mathrm{Ul}$ plays multiple roles in the nucleoplasm of mammalian cells (see below).

An alternative interpretation of our data is that $\mathrm{U} 1 \mathrm{can}$ promiscuously cross-link to any RNA that contains a region complementary to its $5^{\prime}$ end. On the basis of the following observations, we argue that this is unlikely. (1) Using an adenovirus splicing substrate (406 nucleotides long), the only U1 cross-link was to the $5^{\prime}$ splice site, even in the absence of spliceosome formation; crosslinking of $U 1$ to a site in the intron containing 6 of 9 nucleotides that match the consensus $5^{\prime}$ splice site sequence (Mount 1982; Ohshima and Gotoh 1987) was not 
detected (D. Wassarman and Steitz 1992). (2) As shown in Figure 1B, a histone pre-mRNA substrate does not detectably cross-link to U1 although it contains at least three potential Ul base-pairing interactions (including

\section{UGGUGGG-H3 \\ $\mathrm{GG}_{\mathrm{UCCAUUC}} \mathrm{C} 1$}

upstream of the histone processing site), which appear to be better than the interactions identified here (see Fig. 4). (3) A substrate containing external transcribed spacer sequences from rRNA also does not cross-link to U1 snRNA (data not shown; Tyc and Steitz 1992). Once again, there are two regions of complementarity to the $5^{\prime}$ end of U1 in this 650-nucleotide-long substrate containing 7 of 9 nucleotides that match the consensus $5^{\prime}$ splice site sequence. (4) The SV40 late and L3 substrates analyzed in this paper possess other regions of potential base-pairing with the $5^{\prime}$ end of U1, which contain 6 or 7 of 9 nucleotides that match the $5^{\prime}$ splice site consensus sequence; yet, cross-linking was only observed to the sites mapped. (5) Finally, if U1 binding to polyadenylation substrates were promiscuous, a single point mutation (AG $\rightarrow$ AA) located 50 nucleotides upstream of the cross-linking site on the SV40 late coupled substrate would not be expected to change the efficiency of crosslinking. To rule out the possibility that this single-base change leads to increased accessibility of wild-type substrate compared with $3^{\prime}$ splice site mutant substrate, the substrates were subjected to RNase Tl and RNase A digestion in nuclear extract after preincubation under cross-linking conditions (see Materials and methods). The digestion patterns of the two substrates between the $3^{\prime}$ splice site and poly(A) signal were indistinguishable (data not shown), indicating that there is equal accessibility in this region. We suggest that the $\mathrm{Ul}$ association with polyadenylation substrates that we have observed is specific and functionally relevant.

It has been well documented that in vitro polyadenylation using fractionated components does not require a snRNP (see Wahle and Keller 1992); however, several previous studies suggested that a snRNP, possibly U1, may associate with the polyadenylation site in crude extracts. Antibodies that target the Sm epitope as well as some anti-(U1)RNP sera inhibit polyadenylation in vitro (Moore and Sharp 1984). RNase protection studies identified regions of polyadenylation substrates specifically selected with antibodies against Sm or the TMG cap (Hashimoto and Steitz 1986). Most intriguingly, immunoprecipitation experiments using antibodies against poly|A) polymerase specifically enriched for the U1 snRNP (Raju and Jacob 1988).

Features of the U1 snRNP also indicate that it may have functions in addition to splicing. $U 1$ is twoto threefold more abundant than the other spliceosomal snRNPs (Reddy and Busch 1988). In the mammalian nucleoplasm, in addition to being found with the other splicing snRNPs in coiled bodies and speckles (Huang and Spector 1992), a portion of the U1 snRNP is more widely distributed (Carmo-Fonseca et al. 1991, 1992; Matera and Ward 1993). Intriguingly, the nuclear local- ization of a polyadenylation factor (CstF) also shows a diffuse, granular staining pattern (Takagaki et al. 1990). In Xenopus oocytes, again, all of the splicing snRNPs are found in B snurposomes, whereas only the U1 snRNP is found in A snurposomes (Wu et al. 1991). Even the role of the U1 snRNP in splicing appears to be more complicated than simply base-pairing to the $5^{\prime}$ splice site (see introductory section).

Evidence for U1 snRNP involvement in communication across internal exons to facilitate splicing is accumulating. The binding of $U 1$ snRNP at a downstream $5^{\prime}$ splice site of a multi-intron-containing pre-mRNA directly affects the excision of the adjacent upstream intron (Grabowski et al. 1991; Kuo et al. 1991), perhaps by mediating complex formation at the upstream $3^{\prime}$ splice site (Hoffman and Grabowski 1992). At the $3^{\prime}$ end of a pre-mRNA, the terminal exon does not contain a downstream $5^{\prime}$ splice site but does contain a polyadenylation site; therefore, it has been proposed that the $3^{\prime}$-terminal exon is defined by the presence of an upstream 3 ' splice site and a downstream polyadenylation site (Niwa et al. 1990; Niwa and Berget 1991). In agreement with this model, our data implicate the Ul snRNP in communication across a 3 '-terminal exon, perhaps similar to its role in defining internal exons.

Analyses of the human immunodeficiency virus (HIV) env mRNA have suggested that the Ul snRNP may also function in the transport of mature messages out of the nucleus. The env mRNA was exported only when it contained sequences complementary to the $5^{\prime}$ end of the U1 snRNA, a conclusion elegantly supported by genetic suppression data (Lu et al. 1990). We observed cross-linking of Ul snRNA to the polyadenylated RNA product, as well as to the pre-mRNA using the SV40 late substrate (data not shown), indicating that the Ul snRNP does remain associated with the substrate after processing. Processing of pre-mRNA and subsequent transport of the mature mRNA must be highly coordinated; thus, it is attractive to speculate that the U1 snRNP plays a role in relating these processes.

What is the mechanism by which the Ul snRNP might contribute to communication across terminal exons? One simple idea is that after $\mathrm{Ul}$ is recruited to a pre-mRNA, it diffuses along the RNA strand and is halted by a stop signal; this signal could be a specific complementary sequence (e.g., a 5' splice site) or another macromolecular complex bound to the RNA (e.g., a $3^{\prime}$ splice site or polyadenylation complex). It should be noted that the Ul snRNP may not directly require its $5^{\prime}$ end to function in the coupling of splicing and polyadenylation, similar to its observed interaction with the $3^{\prime}$ end of introns (Fu and Maniatis 1992), its role in splicing of unusual messages (Bruzik and Steitz 1990), and its interaction with U2 snRNP (Daugeron et al. 1992). The mutational analyses shown here suggest that the U1binding sites that we have mapped on polyadenylation substrates may not in themselves represent functional sites but reflect an increase in the local concentration of U1 snRNP under coupled conditions; psoralen crosslinking fixes a normally fleeting interaction between the 
pre-mRNA and the U1 snRNP during its diffusional pathway. In such a model, substrates that show a decreased binding of $\mathrm{U} 1$ at the cross-linking site would have no effect on coupling, as seen, because the Ul snRNP needs to bypass this region to reach the polyadenylation machinery. However, introducing a strong U1binding site such as a consensus $5^{\prime}$ splice site sequence produces a stop signal that prevents communication from proceeding downstream and thus abolishing the coupling of splicing and polyadenylation. It should be noted that although the mutant substrates show a decrease/increase in U1 snRNA cross-linking, this does not necessarily represent a decrease/increase in U1 snRNP associated with the substrates because we have mutated the point of interaction at which the cross-linking is known to take place. Insertion of an actual $5^{\prime}$ splice site and surrounding sequences ( $\sim 75$ nucleotides) into a 3 '-terminal exon has been shown recently to abolish the coupling of splicing and polyadenylation (Niwa et al. 1992); we demonstrate here that a 5' splice site consensus sequence suffices to abolish coupling. The observation that $5^{\prime}$ splice site consensus sequences are distributed nonrandomly throughout 3 '-terminal exons (Brunak et al. 1991) further supports this model.

Whatever the specific mechanism, the data presented here suggest that recognition of and communication across internal and terminal exons similarly involve the U1 snRNP and its apparent ability to recognize appropriate processing signals. Given the large size of $3^{\prime}$ terminal compared with internal exons in most premRNAs, it is also possible that the Ul-binding sites that we have identified serve as reassociation points and aid in diffusion; in such a model, the U1-binding sites would be expected to be relatively weak to allow efficient dissociation. Such effects may not be apparent in our in vitro system in which the terminal exon is abnormally short. In any case, we have established a clear correlation between the presence of the U1 snRNP on the 3 '-terminal exon and conditions that couple splicing and polyadenylation.

\section{Materials and methods}

\section{Polyadenylation reactions}

Standard in vitro poly(A) addition and polyadenylation cleavage reactions were performed basically as described previously [K.Wassarman and Steitz 1992; Figs. 1, 2, 3, 5, and 6]. Conditions were optimized for the coupling of polyadenylation and splicing by titering the $\mathrm{MgCl}_{2}$ concentration and using conditions described previously (Niwa et al. 1990). Optimal coupled poly(A) addition and cleavage activities were observed at $1.5 \mathrm{~mm}$ $\mathrm{MgCl}_{2}$ for nuclear extracts prepared with $\mathrm{MgCl}_{2}$ (Dignam et al. 1983) (Figs. 7 and 8). Polyadenylation reactions were used either for psoralen cross-linking or to test the extent of polyadenylation. For experiments with 2'-O-Me oligonucleotides, the oligonucleotides were added directly to the polyadenylation reaction mixtures at the concentrations indicated. Substrates were in vitro-transcribed with $\left[\alpha^{32} \mathrm{P}\right]$ UTP unless otherwise indicated.

Polyacrylamide gels fractionating processing reactions were scanned with a PhosphorImager (Molecular Dynamics) to assess the polyadenylation activity. The efficiency of polyadenylation was calculated as the percentage of radioactivity in the product compared with the total amount of radioactivity in the substrate and product bands for each individual lane. This method of quantitation enables values from each lane to be compared without an internal control for variability in sample loading. All substrates examined exhibited comparable, but very low, levels of degradation in nuclear extract (data not shown; see Fig. 8).

\section{Psoralen cross-linking assays}

Polyadenylation reactions were incubated for $10 \mathrm{~min}$ at $30^{\circ} \mathrm{C}$ before cross-linking. Psoralen cross-linking was done according to Hausner et al. (1990): The sample was transfered to parafilm on ice in drops of no more than $100 \mu \mathrm{l}$ followed by the addition of one-tenth volume of $60 \mu \mathrm{g} / \mathrm{ml}$ psoralen $/ 4^{\prime}$-aminomethyl4,5',8-trimethylpsoralen; HRI Associates) and irradiated with $365 \mathrm{~nm}$ light for $10 \mathrm{~min}$. An additional one-tenth original volume of $60 \mu \mathrm{g} / \mathrm{ml}$ psoralen was added, and the samples were irradiated for another $10 \mathrm{~min}$ on ice. Cross-linked samples were pooled, and SDS and proteinase $\mathrm{K}$ were added to $1 \%$ and $1 \mathrm{mg} /$ $\mathrm{ml}$ final concentrations, respectively, and incubated at $65^{\circ} \mathrm{C}$ for $20 \mathrm{~min}$. The S-100 extract (Fig. 2) was prepared as described previously (Dignam et al. 1983)

Irradiated RNAs were immunoprecipitated with monoclonal anti-TMG antibodies (Oncogene Scientific) as described previously (Steitz 1989) for the experiment shown in Figure 1. Crosslinked RNAs were analyzed on denaturing polyacrylamide gels. Quantitation of cross-linking efficiency was done by PhosphorImager analyses as described above for polyadenylation reactions. Two-dimensional gels were as described (D. Wassarman and Steitz 1992); psoralen cross-links were photoreversed after the first gel with $254 \mathrm{~nm}$ light at $4^{\circ} \mathrm{C}$ for $20 \mathrm{~min}$ and then fractionated on a second gel.

\section{RNase digestion}

RNase $\mathrm{H}$ digestions were performed on immunoprecipitated, cross-linked RNAs in $2.2 \mathrm{mM} \mathrm{MgCl} 2,0.5 \mathrm{~mm} \mathrm{ATP}, 0.04 \mathrm{U} / \mu \mathrm{l}$ of RNase inhibitor (Boehringer Mannheim), $0.05 \mathrm{U} / \mu$ l of RNase $\mathrm{H}$ (Pharmacia), and $0.04 \mu \mathrm{g} / \mu \mathrm{l}$ of deoxyoligonucleotide at $30^{\circ} \mathrm{C}$ for $45 \mathrm{~min}$.

RNase Tl digestions for mapping the sites of cross-linking were performed on RNA isolated from polyacrylamide gels by incubation in $20 \mathrm{~mm}$ sodium citrate $(\mathrm{pH} 5.0), 1 \mathrm{~mm}$ EDTA, $7 \mathrm{M}$ urea, $0.02 \%$ xylene cyanol FF, $0.04 \%$ bromphenol blue, 2-10 $\mu \mathrm{g}$ of carrier RNA, and $10 \mathrm{U} / \mu \mathrm{l}$ of RNase T1 (Calbiochem) at $55^{\circ} \mathrm{C}$ for $30 \mathrm{~min}$ (Donis-Keller et al. 1977). Samples were analyzed directly on two-dimensional gels as described above.

RNase $A$ and $T 1$ digestions for secondary structure analyses of the Ad3'SS(AA)-SVLPA and Ad3'SS(AG)-SVLPA substrates were carried out in standard polyadenylation cleavage reactions. Reactions of $250 \mu \mathrm{l}$ were incubated for $10 \mathrm{~min}$ at $30^{\circ} \mathrm{C}, 0.0025$ 0.025 units of RNase T1 or $0.0025-0.025 \mu \mathrm{g}$ of RNase A was added, and the reactions were incubated further at room temperature for 10 additional min. Isolated RNA was analyzed by primer extension (K. Wassarman and Steitz 1992) using the SV-B oligonucleotide as primer.

\section{Oligonucleotides and plasmids}

2'-O-Me oligonucleotides (Glen Research) were purified over Sephadex G-25 gel filtration columns in water before use. The $\mathrm{U} 1_{1-14}$ oligonucleotide is complementary to the first 14 nucleotides of the Ul snRNA (UGCCAGGUAAGUAU), and the nonspecific $2^{\prime}$-O-Me oligonucleotide is GCAAACCUCUAGG. Deoxyoligonucleotides were synthesized by John Flory (Yale 
University, New Haven, CT) and were gel purified and desalted on Sep Pak C18 cartridges (Waters). The sequences of the oligonucleotides are as follows: U1L2, CGGAGTGCAATG; SV-A, ATGTCTGGATCCCCG; SV-B, TTTCACTGCATTCTA; SVD, ATGCAATTGTTGTTG; L3-A, ACAAGCTTTTGTTCC; L3-B, TTATTGAAAGTGTCT; L3-D， GACGGCAAGGGTGGG; nonspecific deoxyoligonucleotide, GCTAGAAACTCGAACCGATTCCTCTC.

The plasmids pSPSV40 $-141 /+70$ /Zarkower and Wickens 1987), pT3L3 (Skolnik-David et al. 1987), and pSPmH33' (Mowry and Steitz 1987) were used to generate the SV40 late, adenovirus $\mathrm{L} 3$, and histone $\mathrm{H} 3$ substrates, respectively. The plasmid pSPAd3'SS(AG)-SVL used to generate the Ad3'SSSVLPA wild-type substrate was constructed as follows. A ScaI fragment containing the $3^{\prime}$ splice site from pSPAd was cloned into the filled-in BamHI site in pSPSV40 $-141 /+70$, followed by excision of the HindIII fragment containing the 3 ' splice site and polyadenylation signal and subsequent ligation into the HindIII site in pSP64. An M13mpl8 derivative containing a NheI-SacI fragment from pSPAd was made (provided by $D$. Wassarman), and the AG $\rightarrow$ AA mutation at the $3^{\prime}$ splice site was generated by mutagenesis as described previously (Kunkel et al. 1987) to generate pM13mpl8-Ad3'SS(AA). pSPAd3'SS(AA)SVL was cloned as described above using pM13mp18Ad3'SS(AA) instead of pSPAd. To generate the Ad3'SS-SVLPA mutant substrates, the SphI-EcoRI fragments from pSPAd3'SS(AG)-SVLPA and pSPAd3'SS(AA)-SVLPA were cloned into $M 13 \mathrm{mp} 18$ and subjected to mutagenesis (Kunkel et al. 1987). The HindIII fragments containing the mutant sequences were then ligated back into the HindIII site in pSP64.

\section{Acknowledgments}

We thank D. Wassarman, K. Tyc, E. Sontheimer, V. Myer, and the rest of the Steitz laboratory for advice and criticism throughout the course of this work. We also thank M. Niwa and S. Berget for useful discussions. This work was supported by grant GM26154 from the National Institutes of Health.

The publication costs of this article were defrayed in part by payment of page charges. This article must therefore be hereby marked "advertisement" in accordance with 18 USC section 1734 solely to indicate this fact.

\section{References}

Barabino, S.M.L., B.J. Blencowe, U. Ryder, B.S. Sproat, and A.I. Lamond. 1990. Targeted snRNP depletion reveals an additional role for mammalian U1 snRNP in spliceosome assembly. Cell 63: 293-302.

Birnstiel, M.L. and F.J. Schaufele. 1988. Structure and function of minor snRNPs, In Structure and function of major and minor small nuclear ribonucleoprotein particles (ed. M.L. Birnstiel), pp. 155-182. Springer-Verlag, Berlin, Germany.

Brunak, S., J. Engelbrecht, and S. Knudsen. 1991. Prediction of human mRNA donor and acceptor sites from the DNA sequence. I. Mol. Biol. 220: 49-65.

Bruzik, J.P. and J.A. Steitz. 1990. Spliced leader RNA sequences can substitute for the essential $5^{\prime}$ end of Ul RNA during splicing in a mammalian in vitro system. Cell 62: 889-899.

Buchman, A.R. and P. Berg. 1988. Comparison of intron-dependent and intron-independent gene expression. Mol. Cell. Biol. 8: 4395-4405.

Carmo-Fonseca, M., D. Tollervey, R. Pepperkok, S.M.L. Barabino, A. Merdes, C. Brunner, P.D. Zamore, M.R. Green, E.
Hurt, and A.I. Lamond. 1991. Mammalian nuclei contain foci which are highly enriched in components of the premRNA splicing machinery. EMBO I. 10: 195-206.

Carmo-Fonseca, M., R. Pepperkok, M.T. Carvalho, and A.I. Lamond. 1992. Transcription-dependent colocalization of $\mathrm{U} 1$, $\mathrm{U} 2, \mathrm{U} 4 / \mathrm{U} 6$, and U5 snRNPs in coiled bodies. $/$. Cell Biol. 117: 1-14.

Cimino, G.C., H.B. Gamper, S.T. Isaacs, and J.E. Hearst. 1985. Psoralens as photoactive probes of nucleic acid structure and function: Organic chemistry, photochemistry, and biochemistry. Annu. Rev. Biochem. 54: 1151-1193.

Craig, N., S. Kass, and B. Sollner-Webb. 1987. Nucleotide sequence determining the first cleavage site in the processing of mouse precursor rRNA. Proc. Natl. Acad. Sci. 84: 629633.

Daugeron, M.-C., J. Tazi, P. Jeanteur, C. Brunel, and G. Cathala. 1992. U1-U2 snRNPs interaction induced by an RNA complementary to the $5^{\prime}$ end sequence of U1 snRNA. Nucleic Acids Res. 20: 3625-3630.

Dignam, J.D., R.M. Lebovitz, and R.G. Roeder. 1983. Accurate transcription initiation by RNA polymerase II in a soluble extract from isolated mammalian nuclei. Nucleic Acids Res. 11: 1475-1489.

Donis-Keller, H., A.M. Maxam, and W. Gilbert. 1977. Mapping adenines, guanines, and pyrimidines in RNA. Nucleic Acids Res. 4: $2527-2538$.

Fu, X.-D. and T. Maniatis. 1992. The 35-kDa mammalian splicing factor SC35 mediates specific interactions between $U 1$ and $\mathrm{U} 2$ small nuclear ribonucleoprotein particles at the $3^{\prime}$ splice site. Proc. Nat1. Acad. Sci. 89: 1725-1729.

Grabowski, P.J., F.-U.H. Nasim, H.-C. Kuo, and R. Burch. 1991. Combinatorial splicing of exon pairs by two-site binding of Ul small nuclear ribonucleoprotein particle. Mol. Cell. Biol. 11: 5919-5928.

Green, M.R. 1991. Biochemical mechanisms of constitutive and regulated pre-mRNA splicing. Annu. Rev. Cell Biol. 7: 559599.

Guthrie, C. 1991. Messenger RNA splicing in yeast: Clues to why the spliceosome is a ribonucleoprotein. Science 253: 157-163.

Hashimoto, C. and J.A. Steitz. 1986. A small nuclear ribonucleoprotein associates with the AAUAAA polyadenylation signal in vitro. Cell 45: 581-591.

Hausner, T.-P., L.M. Giglio, and A.M. Weiner. 1990. Evidence for base-pairing between mammalian $\mathrm{U} 2$ and $\mathrm{U} 6$ small nuclear ribonucleoprotein particles. Genes \& Dev. 4: 21462156.

Hoffman, B.E. and P.J. Grabowski. 1992. U1 snRNP targets an essential splicing factor, U2AF65, to the 3' splice site by a network of interactions spanning the exon. Genes \& Dev. 6: 2554-2568.

Huang, M.T.G. and C.M. Gorman. 1990. Intervening sequences increase efficiency of RNA $3^{\prime}$ processing and accumulation of cytoplasmic RNA. Nucleic Acids Res. 18: 937-947.

Huang, S. and D.L. Spector. 1992. U1 and U2 small nuclear RNAs are present in nuclear speckles. Proc. Natl. Acad. Sci. 89: 305-308.

Izaurralde, E. and I.W. Mattaj. 1992. Transport of RNA between nucleus and cytoplasm. Sem. in Cell Biol. 3: 279-288.

Krainer, A.R., T. Maniatis, B. Ruskin, and M.R. Green. 1984. Normal and mutant human beta globin pre-mRNAs are faithfully and efficiently spliced in vitro. Cell 36: 993-1005.

Kunkel, T.A., F.D. Roberts, and R.A. Zakour. 1987. Rapid and efficient site-specific mutagenesis without phenotypic selection. Methods Enzymol. 154: 367-382.

Kuo, H.-C., F.-U.H. Nasim, and P.J. Grabowski. 1991. Control of 
alternative splicing by the differential binding of U1 small nuclear ribonucleoprotein particle. Science 251: 1045-1050.

Lu, X., J. Heimer, D. Rekosh, and M.-L. Hammarskjold. 1990. U1 small nuclear RNA plays a direct role in the formation of a rev-regulated human immunodeficiency virus env mRNA that remains unspliced. Proc. Natl. Acad. Sci. 87: 75987602.

Matera, A.G. and D.C. Ward. 1993. Nucleoplasmic organization of mammalian snRNPs. J. Cell Biol. (in press).

Michaud, S. and R. Reed. 1991. An ATP-independent complex commits pre-mRNA to the mammalian spliceosome assembly pathway. Genes \& Dev. 5: 2534-2546.

Moore, C.L. and P.A. Sharp. 1984. Site-specific polyadenylation in a cell-free reaction. Cell 36: 581-591.

1985. Accurate cleavage and polyadenylation of exogenous RNA substrate. Cell 41: 845-855.

Mount, S.M. 1982. A catalogue of splice junction sequences. Nucleic Acids Res. 10: 459-472.

Mowry, K.L. and J.A. Steitz. 1987. Both conserved signals on mammalian histone pre-mRNAs associate with small nuclear ribonucleoproteins during $3^{\prime}$ end formation in vitro. Mol. Cell. Biol. 7: 1663-1672.

- 1988. snRNP mediators of 3 ' end processing: Functional fossils? Trends Biochem. Sci. 13: 447-451.

Niwa, M. and S.M. Berget. 1991. Mutation of the AAUAAA polyadenylation signal depresses in vitro splicing of proximal but not distal introns. Genes \& Dev. 5: 2086-2095.

Niwa, M., S.D. Rose, and S.M. Berget. 1990. In vitro polyadenylation is stimulated by the presence of an upstream intron. Genes \& Dev. 4: 1552-1559.

Niwa, M., C.C. MacDonald, and S.M. Berget. 1992. Are vertebrate exons scanned during splice-site selection? Nature 360: $277-280$.

Ohshima, Y. and Y. Gotoh. 1987. Signals for the selection of a splice site in pre-mRNA. Computer analysis of splice junction sequences and like sequences. $J$. Mol. Biol. 195: 247259.

Pandey, N.B., N. Chodchoy, R.-J. Liu, and W.F. Marzluff. 1990. Introns in histone genes alter the distribution of $3^{\prime}$ ends. Nucleic Acids Res. 18: 3161-3170.

Raju, V.S. and S.T. Jacob. 1988. Association of poly(A) polymerase with U1 RNA. J. Biol. Chem. 263: 11067-11070.

Reddy, R. and H. Busch. 1988. Small nuclear RNAs: RNA sequences, structure, and modifications, In Structure and function of major and minor small nuclear ribonucleoprotein particles (ed. M.L. Birnstiel), pp. 1-37. Springer-Verlag, Berlin, Germany.

Reich, C.I., R.W. VanHoy, G.L. Porter, and J.A. Wise. 1992. Mutations at the $3^{\prime}$ splice site can be suppressed by compensatory base changes in U1 snRNA in fission yeast. Cell 69: 1159-1169.

Robberson, B.L., G.J. Cote, and S.M. Berget. 1990. Exon definition may facilitate splice site selection in RNAs with multiple exons. Mol. Cell. Biol, 10: 84-94.

Ruby, S.W. and J. Abelson. 1988. An early hierarchic role of U1 small nuclear ribonucleoprotein in spliceosome assembly. Science 242: 1028-1035.

Seraphin, B. and M. Rosbash. 1989. Identification of functional Ul snRNA-pre-mRNA complexes committed to spliceosome assembly and splicing. Cell 59: 349-358.

Skolnik-David, H., C.L. Moore, and P.A. Sharp. 1987. Electrophoretic separation of polyadenylation-specific complexes. Genes \& Dev. 1: 672-682.

Sproat, B.S., A.I. Lamond, B. Beijer, P. Neuner, and U. Ryder. 1989. Highly efficient chemical synthesis of $2^{\prime}$-O-methyloligoribonucleotides and tetrabiotinylated derivatives; novel probes that are resistant to degradation by RNA or DNA specific nucleases. Nucleic Acids Res. 17: 3373-3386.

Steitz, J.A. 1989. Immunoprecipitation of ribonucleoproteins using autoantibodies. Methods Enzymol. 180: 468-481.

Steitz, J.A., D.L. Black, V. Gerke, K.A. Parker, A. Kramer, D. Frendewey, and W. Keller. 1988. Functions of the abundant $\mathrm{U}$ snRNPs. In Structure and function of major and minor small nuclear ribonucleoprotein particles. /ed. M.L. Birnstiel), pp. 115-154. Springer-Verlag, Berlin, Germany.

Takagaki, Y., J.L. Manley, C.C. MacDonald, I. Wilusz, and T. Shenk. 1990. A multisubunit factor, CstF, is required for polyadenylation of mammalian pre-mRNAs. Genes \& Dev. 4: 2112-2120.

Tyc, K. and J.A. Steitz. 1992. A new interaction between the mouse $5^{\prime}$ external transcribed spacer of pre-rRNA and U3 snRNA detected by psoralen crosslinking. Nucleic Acids Res. 20: 5375-5382.

Wahle, E. and W. Keller. 1992. The biochemistry of 3 '-end cleavage and polyadenylation of messenger RNA precursors. Annu. Rev. Biochem. 61: 419-440.

Wassarman, D.A. and J.A. Steitz. 1992. Interactions of small nuclear RNAs with precursor messenger RNA during in vitro splicing. Science 257: 1918-1925.

Wassarman, K.M. and J.A. Steitz. 1992. The low-abundance U11 and U12 small nuclear ribonucleoproteins (snRNPs) interact to form a two-snRNP complex. Mol. Cell Biol. 12: 12761285.

Wu, Z., C. Murphy, H.G. Callan, and J.G. Gall. 1991. Small nuclear ribonucleoproteins and heterogeneous nuclear ribonucleoproteins in the amphibian germinal vesicle: Loops, spheres, and snurposomes. J. Cell Biol. 113: 465-483.

Zarkower, D. and M. Wickens. 1987. Formation of mRNA $3^{\prime}$ termini: Stability and dissociation of a complex involving the AAUAAA sequence. EMBO I. 6: 177-186.

- 1988. A functionally redundant downstream sequence in SV40 late pre-mRNA is required for mRNA 3 '-end formation and for assembly of a precleavage complex in vitro. $I$. Biol. Chem. 263: 5780-5788.

Zillmann, M., S.D. Rose, and S.M. Berget. 1987. U1 small nuclear ribonucleoproteins are required early during spliceosome assembly. Mol. Cell. Biol. 7: 2877-2883. 


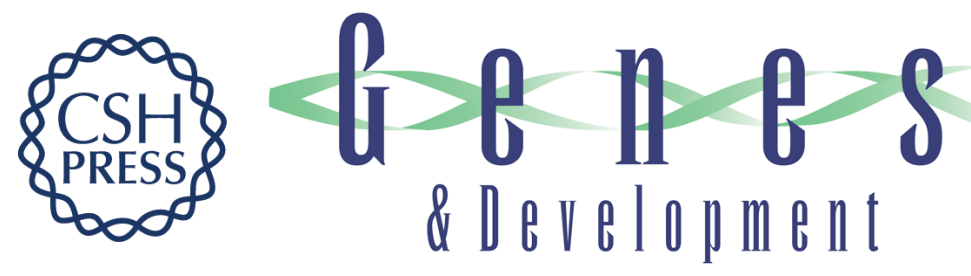

\section{Association with terminal exons in pre-mRNAs: a new role for the U1 snRNP?}

K M Wassarman and J A Steitz

Genes Dev. 1993, 7:

Access the most recent version at doi:10.1101/gad.7.4.647

References This article cites 53 articles, 25 of which can be accessed free at:

http://genesdev.cshlp.org/content/7/4/647.full.html\#ref-list-1

License

Email Alerting Receive free email alerts when new articles cite this article - sign up in the box at the top Service right corner of the article or click here.

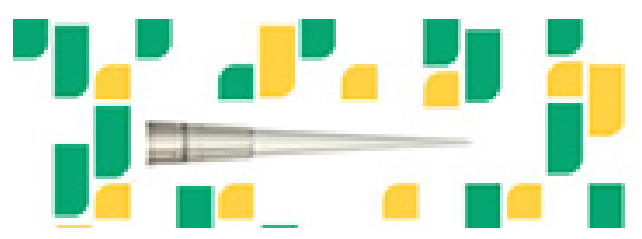

Focused on your science. 